\title{
IMPACT OF GENTRIFICATION ON THE DEGREE OF SATISFACTION OF RESIDENTS IN RESIDENTIAL AREAS
}

\author{
NOORY HAN, YONG-HEE KIM, JEA-SUN LEE \\ Laboratory of Urban Design and Regeneration, Department of Urban Planning, \\ Yonsei University, South Korea
}

\begin{abstract}
In the past 20 years in Seoul, South Korea, there have been continuous changes in deprived urban spaces, and, now, the urban trend that began with redevelopment projects has proceeded to regeneration and gentrification. Many Korean scholars are researching about gentrification-related issues, such as changes in physical environment and process of commercialization; however, researches on residents, the most essential element in urban space, have not been accentuated by the scholars. Consequently, this study attempted to put more emphasis on the residents living in the area. The purpose of this study is to reduce negative impacts of commercial gentrification on residents. It investigated general impacts of gentrification on the area; then, it examined the elements that influence the degree of satisfaction of residents. Finally, through factorial analysis, it verified the effects of gentrification on the study area. The results of the study show that the official land price, the number of building permits, construction permits, and pedestrians have increased. Also, a commercialization has been progressed in the gentrified area, and the overall residential satisfaction has decreased from the satisfaction level to the ordinary level. However, 10 of the 15 indicators of housing satisfaction rose and 5 indicators showed a decline, indicating that a gentrification does not give negative impacts on the region. Lastly, the factor analysis, conducted to figure out factors affecting the resident's satisfaction of the local residents, revealed a degree of influence in the order of comfort, convenience, and accessibility. This study is differentiated from the previous studies for focusing on the residents of the gentrification phenomenon. In order to clarify further phenomenon of gentrification in residential areas and obtain more reliable results, surveys and questionnaires should be conducted to residents who are dissatisfied with the area or already left the area.
\end{abstract}

Keywords: gentrification, degree of satisfaction, commercialization.

\section{INTRODUCTION}

For the past 20 years, various efforts have been made from urban redevelopment to urban regeneration in order to change the backward regions in Seoul, South Korea. In this regard, "Gentrification", a phenomenon in which the backward residential area is replaced by a certain class rather than the existing resident after being reactivated due to commercialization, has become a rising topic. However, most of the studies in South Korea mainly focus on the trends of gentrification, physical environment change, and analysis of the commercialization process, and there is no research on residents, which is one of the most important factors in urban environment.

The purpose of this study is to investigate residents living in the area from the physical and commercial viewpoint of the city. Also, it will analyze how the effect of the gentrification phenomenon affects the region and the resident's satisfaction on the assumption that the commercial gentrification phenomenon will affect the place and residential satisfaction of residents.

\subsection{Scope}

The scope of this study can be divided into contents, spatial, and temporal scopes. First of all, the scope of contents is the definition and influence of the gentrification, and the factors 
that may affect the residential satisfaction of the resident's due to the gentrification. Spatial coverage includes Yeonnam-dong, Mapo-gu, Seoul, and Itaewon2-dong, Yongsan-gu, Seoul, where commercial gentrification phenomenon is currently the most active in Seoul. Finally, the data on the gentrification sites were constructed and analyzed from 2008 to 2015, and surveys on the residential satisfaction of local residents were conducted from May 26, 2016 to June 7, 2016.

\subsection{Method}

This study investigated how physical and nonphysical changes due to gentrification affected the region and investigated how the residents' satisfaction with housing changed as follows.

1. This study examined the influence of gentrification through preliminary research and theoretical review, and examined the elements of housing satisfaction measured by residents.

2. Based on the residential satisfaction factors derived from previous studies, it surveyed residents' satisfaction with the residents residing in two selected sites over 5 years.

3. The results of the survey were statistically analyzed with paired t-test, factor analysis, multiple regression analysis, and frequency analysis. Based on the analyzed results, physical and non-physical effects of gentrification occurred at the site and the housing satisfaction factors that affected residents were derived.

\section{LITERATURE REVIEW}

\subsection{Gentrification}

The term gentrification was first used in 1964 by the British sociologist Ruth Glass to explain the phenomenon of urban change, where low-income residences in London were replaced by high-income and middle-class residential areas. Since then, the phenomenon of gentrification has been studied extensively in many places in the city. In this study, it examines the phenomenon of commercial gentrification in residential areas.

Zukin defined gentrification as a retail landscape that is transformed into a place for upscale consume. The old residential areas in the downtown area, which had not been attracted to the relative attention due to the suburbanization, were renovated with aesthetic value, leading to an increase in the value of potential rents [1]. The study area is experiencing gentrification similar to what Zukin called, so it is defined as the phenomenon that the backward residential area is reactivated by commercialization. This is a series of processes in which localities are transformed and commercialized by a movement of a certain class rather than the existing residents in an underdeveloped area next to an active commerce area such as downtown and sub-urban areas or a region rich in history and cultural resources.

\subsection{Physical and non-physical impact of gentrification}

\subsubsection{Physical impact}

Most studies on existing gentrification have focused on physical changes and have confirmed the relationship between changes in roadside and gentrification. The researches that deal with the physical changes are characterized by the fact that the site is located in the old city area and focused on the physical changes due to the expansion of the commercial area in the low-rise residential area. Especially, in the case of Zukin, the process of creating new 
entrepreneurial shops such as boutiques, gallery cafes, restaurants, and interior accessories shops [2].

This study reviewed a number of Korean papers, and most of the previous researches have focused on physical changes, especially on physical forms such as new construction, extension, renovation, and remodelling. In this study, it tries to analyze by using statistical data which is primary data. Therefore, it will focus on the physical changes such as new construction, major repair, change of building usage, number of business, and report of business.

\subsubsection{Non-physical impact}

Most of the existing studies focused on physical changes of gentrification. However, not only the physical impact but also the non-physical impact is also very important and largely influential to localities. Zukin analyzed not only the physical changes due to the entry of new entrepreneurial shops but also various perspectives, and urged policy changes [2].

The studies of non-physical impact of gentrification in Korea have been studied in relation to the change of the number of pedestrians, the change of the land value, and the change of the symbolic ownership. Ahyun Song revealed the symbolic ownership and the change of local image in the commercialization process of the residential area in case of Yunnam-dong area [3].

In this study, it analyzes statistical data related to non-physical changes such as land price, number of pedestrians, sales, and regional image in order to figure out the non-physical change of commercial gentrification.

\subsection{Positive and negative impact of gentrification}

\subsubsection{Positive impact}

Gentrification has a lot of influence on the society, and there are many changes in the urban space due to the gentrification. In particular, gentrification is being actively carried out for various reasons in commercial areas in Korea such as Hongdae, Garosu Street, Samcheongdong, Gyungridan Street, Suchon, and Yeonnam-dong. Gentrification in the commercial space has been positively evaluated in terms of spontaneous revitalization of the underdeveloped urban areas, and is adding to the rise of new places of consumption. In addition, it has been positively evaluated because it can increase the local government's tax revenue and bring the middle class back into the city [4]. Gentrification changes the area making similar kinds of groups match each other, and it prevents the social conflict and makes new neighborhood. Furthermore, the declining region has stabilized and the real estate value of the region has risen [5].

\subsubsection{Negative impact}

Gentrification can be a source of concern because of excessive commercialization. According to various media, new upper class entering the downtown area increases the rents, so that the existing residents and merchants are being kicked out. In the case of low-income households, due to the limitation of housing costs, there is restriction on the choice of the residence and falling into the homeless.

\subsection{Residential satisfaction}

Housing satisfaction is an emotional response to the social, natural, and physical environment in which people live. From the perspective of residents' satisfaction with residential services, residential satisfaction means the level of subjective satisfaction of residents. The importance 
of residential satisfaction was firstly mentioned by Fried and Gleicher, and it was defined as the most appropriate criterion for evaluating residents' satisfaction and residential quality among various types of residence concepts and forms. Francescato et al. and Craik and Zube found that by measuring housing satisfaction, they could induce public institution 's efforts to improve the current residential environment. Since then many studies on the satisfaction of housing have been studied based on various variables, and many studies have been conducted in Korea. Han defined residential satisfaction as the degree of subjective satisfaction of the residents in residential housing [6]. Choi showed that characteristics of the various variables surrounding the resident area affects the decisions of the residents on the choice of housing [7]. This means that the value of the housing meets the purpose and the desire of the human being, and the internal and external housing environment of the house should be done together.

\section{STUDY DESIGN}

\subsection{Selection of study area}

The candidates of the study area were selected from the areas of commercial gentrification in Seoul. Commercial gentrification phenomenon occurs mainly in residential areas and semi-residential areas, and is happening in low-rise residential areas adjacent to core commercial areas. The candidates of gentrification-occurred area for the analysis is mainly located in the vicinity of the nearby commercial and historical cultural properties and has a low rental rate compared to the core commercial areas. In the end, Yeongnam-dong and Itaewon 2-dong were selected.

\subsection{Research question}

The purpose of this study is to investigate the physical and non-physical effects of gentrification on the region through theoretical considerations. As a result, it can be seen that the influence of the gentrification is influenced by the change of the area and the residents living in the area. So, how does the effect of the gentrification affect the local people? The following detailed questions were derived from the question.

1. What are the changes in the area due to the effects of commercial gentrification?

2. How has the residential satisfaction of residents living in the area changed as a result of the phenomenon of gentrification? What are the residential satisfaction factors that affect satisfaction?

\subsection{Variables setting for residential satisfaction}

The variables of residential satisfaction which are considered to affect the satisfaction of residence in the residential area were set up primarily by the gentrification prior to setting the variables. In order to ensure the reliability and accuracy of the selected factors, it conducted a questionnaire consisting of 30 experts who were studying gentrification or practicing directly, and revised and supplemented the elements through questionnaires. As a result, it excluded three variables which were considered to have no effect on residential satisfaction due to the effect of the gentrification. Among the variables, "pedestrian safety and convenience" were classified into "pedestrian safety" and "walking convenience". Table 1 shows the 18 selected housing satisfaction variables for this study. 
Table 1: Selected variables.

\begin{tabular}{|c|c|}
\hline Variables & Selected Variables \\
\hline Cleanliness of roads and walkways & Cleanliness of roads and walkways \\
\hline \multirow{2}{*}{ Pedestrian safety and convenience } & Pedestrian safety \\
\hline & Pedestrian Convenience \\
\hline Parking Space & Parking Space \\
\hline Educational Environment & Educational Environment \\
\hline Convenience of commuting & Convenience of commuting \\
\hline Local Image & Local Image \\
\hline Property value & Property value \\
\hline Investment value & Investment value \\
\hline Place Attachment & Place Attachment \\
\hline Privacy & Privacy \\
\hline Noise Pollution & Noise Pollution \\
\hline Security and Crime & Security and Crime \\
\hline Ease of use of leisure facilities & Ease of use of leisure facilities \\
\hline Ease of use of neighborhood facilities & Ease of use of neighborhood facilities \\
\hline Ease of use of cultural facilities & Ease of use of cultural facilities \\
\hline Use of car & Use of car \\
\hline Residential level of local residents & Residential level of local residents \\
\hline Meeting place of villagers & \multirow[t]{3}{*}{ Excluded } \\
\hline Disaster safety & \\
\hline Relationship with neighbors & \\
\hline
\end{tabular}

\subsection{Survey design}

The questionnaire was conducted at Yeonnam-dong, Mapo-gu, Seoul, and Itaewon2-dong, Yongsan-gu, Seoul. The questionnaire was conducted for a total of 13 days from May 26, 2016 to June 7, 2016 for residents who live for more than five years based on the administrative boundaries of the two sites. The total number of questionnaires was 123, but the two questionnaires were excluded, which were unresponsive and unanswered. 121 valid questionnaires were obtained from the two sites. The questionnaire included general characteristics of the respondents, including gender, age and occupation, years of residence and type of building. The main content of the questionnaire is to compare the level of residential satisfaction between 2011 and 2016, and to measure the level of overall residential satisfaction and how the score of the factors that constitute residential satisfaction changed. The outline is shown in Table 2.

\section{ANALYSIS METHOD}

\subsection{Analysis on local impact of gentrification}

In order to analyze more precisely the change of the influence of the gentrification phenomenon in the area, it constructed a time series analysis data of 9 years based on the data from 2007 to 2015. By constructing this data, it was thought that it would be possible to analyze not only the commercial area but also the change of the living area. Therefore, it analyzed the changes due to the gentrification of the site by conducting a cross-sectional 
Table 2: Outline of survey.

\begin{tabular}{|l|l|}
\hline Category & State \\
\hline Area & $\begin{array}{l}\text { Yeonnam-dong, Mapo-gu, Seoul } \\
\text { Itaewon2-dong, Yongsan-gu, Seoul }\end{array}$ \\
\hline Target & Residents residing in the site for more than 5 years \\
\hline Date & May 26, 2016 June 7, 2016 \\
\hline Method & $\begin{array}{l}\text { Random Sampling } \\
\text { Interview Method }\end{array}$ \\
\hline Type & 5 Point Likert Scale, Nominal Scale \\
\hline Contents & $\begin{array}{l}\text { Respondents general, satisfaction with residential } \\
\text { satisfaction factors and overall residential satisfaction }\end{array}$ \\
\hline Total Number of Copies & 121 valid copies of 123 copies \\
\hline
\end{tabular}

analysis and tried to deduce the correlation with the influence of the indicators according to the change of data.

\subsection{Analysis on residential satisfaction}

\subsubsection{Change of satisfaction}

This study measures the satisfaction of residents who have lived in the area for more than 5 years in order to find out how the satisfaction of the residents in the area has changed. During interviews, residents were asked whether they had lived in the area before 2011, which is considered to be before the occurrence of the gentrification phenomenon. The survey was conducted only on residents who had lived before 2011. The questionnaire consisted of 18 housing satisfaction factors about satisfaction before 2011 and after 2016 (5 point Likert scale). The paired t-test was used for the analysis by SPSS statistics21.

\subsubsection{Analysis on satisfaction factor}

In order to investigate the satisfaction factors of residential satisfaction, 18 factors were selected as independent variables to analyze the satisfaction of housing as Table 1 . The dependent variable used overall satisfaction for residential satisfaction. Factor analysis, reliability analysis and multiple regression analysis were used for statistical analysis. Statistical program was SPSS statistics 21.

\section{ANALYSIS RESULT}

\subsection{Analysis on local impact of gentrification}

\subsubsection{Yeonnam-dong}

In Yeonnam-dong, Mapo-gu, the rate of change in many indicators has started to change significantly due to the influence of commercial gentrification in 2011. Among physical changes, the rate of change in construction permits has increased significantly. In 2011, after one big increase, it showed stagnation for a while, and then it increased steadily. Particularly, there is a bigger change in permits of new construction than a change in permits of changing building uses. It is inferred that when a new building is introduced into an undeveloped area, physical changes occur in the neighbourhood. In addition, the number of restaurants has been steadily increasing. 
Among the non-physical changes, the move-in population of Yeonnam-dong decreased on average, while the number of move-out increased. The total population gradually decreased. It is inferred that the quality of housing has declined due to the commercialization of residential areas, the total amount of housing has decreased, and the number of transfers has increased. The number of sales and the price of the house also steadily increase, and it can be seen that the transaction of the house in the surrounding area increases and the price increases. It is believed that this will encourage the departure of the native residents. Finally, the number of pedestrians has increased explosively, and the number of refers to large portal sites has also increased. The commercial gentrification phenomenon has changed the image of the neighbourhood, and visitors are increasing.

\subsubsection{Itaewon2-dong}

The rate of change in many indexes also started to change significantly in 2011 and 2012 in Itaewon2-dong, Yongsan-gu. Like Yeonnam-dong, Itaewon2-dong showed a remarkable physical change. Except for 2009 and 2012, construction permits continued to increase. Not only the construction permits for new construction, but also the construction permits for change of building uses have increased. It is inferred that not only are new stores coming into the underdeveloped area, but also existing buildings are changing for commercial purposes. In addition, the number of restaurants is also increasing sharply.

Looking at non-physical changes, on average, both move-in and move-out transfers of Itaewon2-dong decreased. However, the total population was decreasing because there were more moving out than moving in. This is also attributed by the decrease in the quality of housing and the decrease in the total amount of housing due to commercialization. The standard land price has been steadily rising, and also the number of trades and the price of the residence have steadily increased. Especially, when the number of trades is increasing considerably, it is deduced that the increase of the prices often causes the native residents to dispose of their houses. In addition, the number of pedestrians and the number of refer to large portal sites have increased sharply. It is also deduced that many references in various media changed the image of the area, thereby increasing the number of visitors.

\subsection{Analysis on change of residential satisfaction and satisfaction factor}

\subsubsection{Demographic characteristics}

The demographic characteristics of respondents were $26 \%$ for males and $74 \%$ for females compared to males. By age, $4.1 \%$ of respondents were in their 20 s, $14.6 \%$ in their 30 s, $18.7 \%$ in their 40 s, $22.8 \%$ in their 50 s, $18.7 \%$ in their 60 s and $21.1 \%$ in their 70 s and over. In the case of residence type, $66 \%$ of the residents, $25 \%$ of the charterers, and $9 \%$ of the renters were listed. The residence period was $24 \%$ for less than 10 years, $18 \%$ for less than 20 years, $12 \%$ for less than 30 years, and $46 \%$ for more than 30 years. In the occupation group, homemakers accounted for $62 \%$, private businesses accounted for $15.7 \%$, sales and service accounted for $2.5 \%$, office \& technical accounted for $2.5 \%$, professional \& liberal posts were $4.1 \%$ and others accounted for $13.2 \%$.

\subsubsection{Change of residential satisfaction}

A paired t-test was conducted to examine whether the effects of commercial gentrification had a significant effect on the change of residential satisfaction for the local residents. Test compared with the year 2011 in which Gentrification appeared and the year 2016 in which the survey was conducted. 
Overall Satisfaction level, which was satisfactory level in 2011 (3.64), changed to unsatisfactory level (2.90) in 2016. Except for three factors, "pedestrian safety", "neighbourhood affection", and "investment value", all other factors had a significant impact on residents' satisfaction compared with 2011 and 2016.

Satisfaction with most factors has declined due to the impact of gentrification. Especially, the factors showing the greatest change were the 'cleanliness of roads and walkways', "educational environment", "privacy", and "noise pollution". With the three factors, the average of satisfaction dropped by more than 0.7. It is inferred that the street became dirty and noisy because of the rapid increase of pedestrian's due to commercialization.

The five factors that showed an increase in satisfaction were "regional image", "property value", "using cultural facilities", "ease of using rest and leisure facilities", and "residential level of local residents". It is inferred that the regional image has risen due to the commercialization of the region, the increase of the property value of the region, and increased visitors. In addition, the ease of using rest and leisure facilities has been increased by the introduction of cafes and leisure facilities in the area, and the introduction of cultural

Table 3: Residential satisfaction before and after the gentrification phenomenon.

\begin{tabular}{|c|c|c|c|c|c|c|}
\hline \multirow{2}{*}{$\begin{array}{c}\text { Residential Satisfaction } \\
\text { Factors }\end{array}$} & \multicolumn{2}{|c|}{ Average } & \multicolumn{2}{|c|}{$\begin{array}{l}\text { Standard } \\
\text { deviation }\end{array}$} & \multirow{2}{*}{$\begin{array}{c}\mathrm{t}- \\
\text { value }\end{array}$} & \multirow{2}{*}{$\begin{array}{c}\mathrm{p}- \\
\text { value }\end{array}$} \\
\hline & $\begin{array}{l}\text { Before } \\
(2011)\end{array}$ & $\begin{array}{l}\text { After } \\
(2016)\end{array}$ & $\begin{array}{l}\text { Before } \\
(2011) \\
\end{array}$ & $\begin{array}{l}\text { After } \\
(2016)\end{array}$ & & \\
\hline $\begin{array}{l}\text { Overall Residential } \\
\text { Satisfaction }\end{array}$ & 3.64 & 2.90 & 0.532 & 0.870 & 7.398 & .000 \\
\hline $\begin{array}{l}\text { Cleanliness of roads and } \\
\text { walkways }\end{array}$ & 3.29 & 2.55 & 0.554 & 0.718 & 8.318 & .000 \\
\hline Pedestrian Safety & 2.89 & 2.79 & 0.560 & 0.741 & 1.179 & .241 \\
\hline Pedestrian Convenience & 2.92 & 2.43 & 0.476 & 0.835 & 5.811 & .000 \\
\hline Parking Area & 2.60 & 2.16 & 0.664 & 0.885 & 7.770 & .000 \\
\hline Educational Environment & 3.27 & 2.52 & 0.548 & 0.620 & 11.457 & .000 \\
\hline Convenience of Commuting & 3.13 & 2.93 & 0.515 & 0.680 & 3.159 & .002 \\
\hline Local Image & 2.72 & 3.86 & 0.536 & 0.711 & -13.982 & .000 \\
\hline Property Value & 2.77 & 3.73 & 0.544 & 0.775 & -10.259 & .000 \\
\hline Investment Value & 3.02 & 3.13 & 0.428 & 0.974 & -1.160 & .248 \\
\hline Neighbourhood Affection & 3.61 & 3.61 & 0.637 & 0.579 & .000 & 1.000 \\
\hline Privacy & 3.51 & 2.79 & 0.579 & 0.766 & 10.328 & .000 \\
\hline Noise Pollution & 3.79 & 1.86 & 0.576 & 0.820 & 25.206 & .000 \\
\hline Security & 3.20 & 2.77 & 0.586 & 0.824 & 4.743 & .000 \\
\hline $\begin{array}{l}\text { Ease of Using Rest and } \\
\text { Leisure Facilities }\end{array}$ & 2.71 & 3.69 & 0.554 & 0.669 & -12.225 & .000 \\
\hline $\begin{array}{l}\text { Ease of Using } \\
\text { Neighbourhood Facilities }\end{array}$ & 3.17 & 2.49 & 0.454 & 0.708 & 10.173 & .000 \\
\hline Use of Cultural Facilities & 2.82 & 3.23 & 0.465 & 0.559 & -6.949 & .000 \\
\hline Use of Cars & 2.69 & 2.15 & 0.563 & 0.654 & 10.224 & .000 \\
\hline $\begin{array}{l}\text { Residential Level of Local } \\
\text { Residents }\end{array}$ & 2.83 & 3.23 & 0.506 & 0.680 & -5.842 & .000 \\
\hline \multicolumn{7}{|c|}{${ }^{*} \mathrm{p}<0.05$} \\
\hline
\end{tabular}


facilities has become a factor of satisfaction. It is believed that the increase in rents and housing prices due to commercialization of the area has also increased the residential level of the local residents.

\subsubsection{Factor Analysis}

For the regression analysis of the factors affecting the residential satisfaction of the local residents, factor analysis was performed and the variables with high correlation were tied together. 'Educational environment' and 'ease of using nearby facilities' were excluded because the communality was less than 0.4 .

As a result of the factor analysis, the KMO (Kaiser-Meyer-Olkin) measure was 0.750 , so it was appropriate to select the variables. The communality of 16 elements was more than 0.4 , and it was judged that factor loadings of 0.3 or more were appropriate for all of the rotated component matrices. The four extracted factors and the corresponding variables were classified as shown in Table 4.

Table 4: Results of factor analysis.

\begin{tabular}{|c|c|c|c|c|c|}
\hline \multicolumn{2}{|r|}{ Category } & \multicolumn{4}{|c|}{ Component } \\
\hline & & 1 & 2 & 3 & 4 \\
\hline \multirow[t]{6}{*}{ Comfort } & Noise Pollution & .698 & -.120 & .388 & .174 \\
\hline & Security & .675 & -.002 & .006 & -.395 \\
\hline & Pedestrian Convenience & .629 & .166 & -.039 & .097 \\
\hline & Neighbourhood Affection & .593 & .475 & .094 & .080 \\
\hline & Pedestrian Safety & .532 & .309 & .068 & -.019 \\
\hline & $\begin{array}{c}\text { Cleanliness of roads and } \\
\text { walkways }\end{array}$ & .433 & .270 & .325 & -.318 \\
\hline \multirow[t]{4}{*}{ Convenience } & Local Image & .042 & .819 & .139 & .071 \\
\hline & $\begin{array}{l}\text { Residential Level of Local } \\
\text { Residents }\end{array}$ & .041 & .753 & -.049 & -.033 \\
\hline & $\begin{array}{l}\text { Ease of Using Rest and } \\
\text { Leisure Facilities }\end{array}$ & .449 & .704 & .096 & -.078 \\
\hline & Use of Cultural Facilities & .432 & .474 & .172 & .061 \\
\hline \multirow[t]{4}{*}{ Accessibility } & Use of Cars & -.173 & .134 & .842 & -.138 \\
\hline & Convenience of Commuting & .034 & .448 & .621 & .018 \\
\hline & Privacy & .411 & -.020 & .618 & .253 \\
\hline & Parking Area & .346 & -.074 & .526 & .000 \\
\hline \multirow[t]{2}{*}{ Economics } & Investment Value & -.053 & -.145 & -.006 & .818 \\
\hline & Property Value & .113 & .223 & .031 & .762 \\
\hline & $\begin{array}{l}\text { tion Method } \\
\text { ethod: Varim }\end{array}$ & $\mathrm{mp}$ & & & \\
\hline
\end{tabular}

The reliability analysis was conducted to confirm whether the extracted variables consisted of homogeneous variables through factor analysis. As a result of the reliability analysis, Cronbach a value of "Comfort" was 0.738, "Convenience" was 0.769, “Accessibility” was 0.634 and "Economics" was 0.562. 


\subsubsection{Regression analysis}

Multiple regression analysis was conducted between each factor and overall satisfaction extracted from factor analysis to identify variables that affect residential satisfaction of local residents. Statistical significance was analyzed at significance level 0.05 (t value $>1.96, \mathrm{p}$ $<0.05$ ). Statistical significance was also analyzed at significance level 0.1 ( $\mathrm{t}$ value $>1.96, \mathrm{p}$ $<0.1$ ). The Durbin-Watson index was 1.835, and the regression model was considered appropriate because there was no correlation between the residuals.

As a result of analysis, factors affecting residential satisfaction were "comfort" and "convenience" at $p<0.05$. When the significance level was increased to 0.1 , 'accessibility' was significant. "Comfort" $(0.468)$ was the highest and "convenience" $(0.285)$ was the next most significant factor to affect the residential satisfaction. "Accessibility" (0.125) also had an effect on residential satisfaction.

The variables of 'comfort' factor, which showed the highest level of influence in the multiple regression analysis, were "noise pollution”, "security”, “convenience of walking”, "neighbourhood affection", "pedestrian safety" and "cleanliness of the road and walkway". One of the biggest changes in the region due to the gentrification, the change of the floating population, seems to have the greatest impact on the quality of life of the residents. Especially, it can be deduced that the increase of the floating population had a big impact on the decrease of the satisfaction of the resident's due to the dirty and noisy neighbourhood. It can be deduced that the satisfaction of walking convenience is reduced by increasing the flow population while keeping the walking route narrow. In addition, it can be deduced that the increase in the number of people and vehicles, and the construction and renovation of the building caused dissatisfaction in the safety of walking.

The variables of "convenience" factor, which showed a high level of influence, were "regional image", "residential level of local residents", "ease of use of rest and leisure facilities", and "use of cultural facilities". As a result of the change caused by the gentrification, the commercialization of the area will increase restaurants, cafes, small workshops and galleries. Therefore, it can be inferred that ease of use of rest and leisure facilities and cultural facilities improved the satisfaction of residents. Also, as people refer to the area a lot, the area turns into a charming place, so the image of the area has risen. As a result, housing prices and rents have risen, which can be inferred to have increased the residential level of local residents.

Table 5: Results of regression analysis.

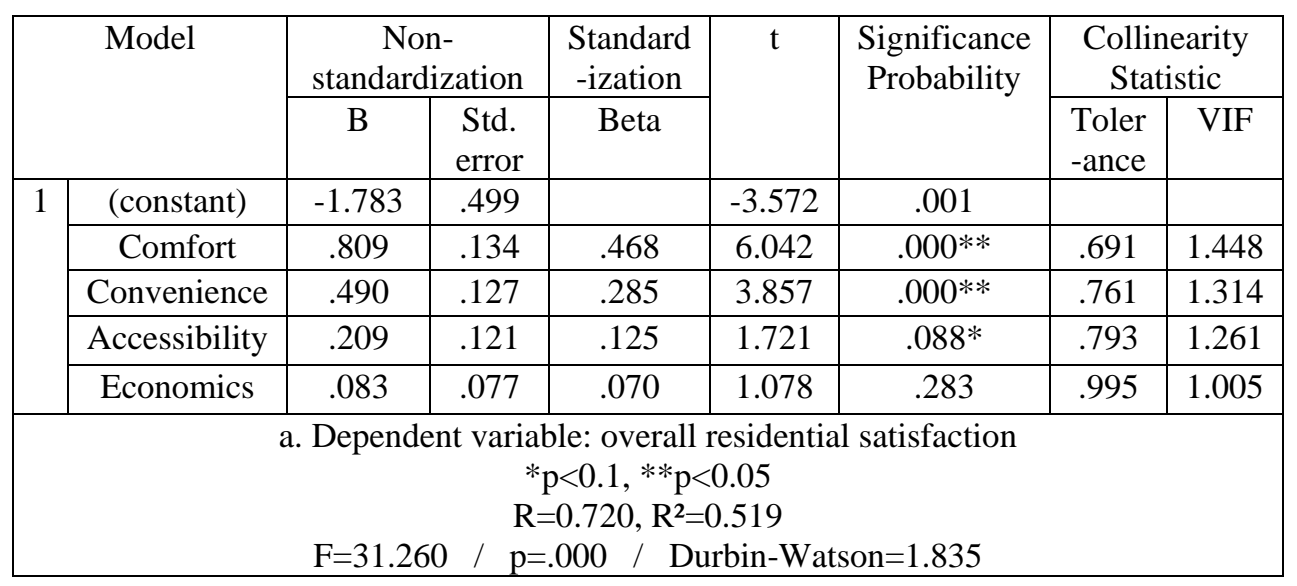


Finally, "Accessibility", which has a significant effect on the significance level of 0.1, consists of variables such as "use of car", "convenience in commuting", "privacy" and "parking space". In the case of accessibility, it can be deduced that there are traffic congestion and traffic problems due to commercialization. Especially, the increase in the number of people who visit a unique shop by car makes it clear that the satisfaction of local residents' use of the car has decreased.

\section{CONCLUSION}

In this study, the effect of gentrification on the residents of the surrounding residential areas was examined. The actual impact of gentrification was investigated and the research was conducted focusing on measuring the satisfaction of residents in the area where gentrification occurred.

First, cross-sectional analysis was conducted by constructing statistical data on changes in previous studies and media in order to determine how physical and non-physical changes are caused by commercial gentrification in the area. As a result, several related indicators have changed drastically in the region based on the specific year 2011. For example, the number of places where restaurants and eateries were first increased sharply. As a result, construction permits, the number of trades, and the official price of land have also risen. Since then, the number of moving out has increased, the number of moving in has decreased, and the area has become commercialized. In addition, as the area became known to the outside world and the number of referrals in large portal sites increased sharply, various indicators such as floating population, restaurants and eateries, building permits, and official land prices also increased steadily.

Second, the questionnaire survey was conducted to investigate how the changes in the area according to the commercial gentrification affected the residential satisfaction of residents. As a result of the analysis, the overall satisfaction of the residents decreased within the statistical significance from "the satisfaction" (3.64) to "the ordinary" (2.90). Of the 15 variables related to residential satisfaction, satisfaction with ten variables, such as "cleanliness of roads and walkways", "convenience of walking”, "parking spaces", "educational environment”, “convenience of commuting”, "privacy”, "noise pollution”, "ease of use of facilities", and "use of car", has decreased. Satisfaction with the other five variables, such as "local image”, "property value”, "ease of use of rest and leisure facilities", "use of cultural facilities", and "residential level of local residents", has increased. In this way, the commercial gentrification increased the economic satisfaction and the satisfaction with "local image" and "the use of facilities in the area", but the residential satisfaction of the residents decreased overall.

Finally, regression analysis showed that "comfort" decreased. As the commercialization progresses, the increase of the floating population causes the noise in the neighbourhood and problems in security. In addition, the number of people increases, the walking becomes uncomfortable, the number of vehicles increases, and the traffic risk increases. It can be inferred that these factors led to a decline in housing satisfaction. To solve this problem, CCTV and integrated management center, which is a kind of ubiquitous city management method, should be introduced. On the other hand, "convenience” increased. It is believed that the commercialization has enabled the residents to enjoy rest and leisure in the new commercial facilities and cultural facilities. It can be interpreted that "accessibility" has affected the decrease in satisfaction. As a result of commercialization, there will be more cars in the area, which means that the inconveniences of commuting and parking at the local residents are increasing. 
This study evaluated the satisfaction of the local residents according to changes in urban space (i.e., gentrification). However, there were limitations of the study as follows. Because there are many changes in the urban space at the same time, it has been difficult to control the influencing factors other than the gentrification. The study area is limited to two places in Yeonnam-dong and Itaewon2-dong. Due to the difficulty of questionnaire survey time, except for housewives and self-employed people, there were not many people in the area, so it was difficult to obtain samples with various characteristics. It has not been possible to conduct surveys on residents who have left the area for reasons such as residential dissatisfaction. However, if people who left the area are included in the questionnaire, the result is even more negative.

\section{ACKNOWLEDGEMENT}

This work is financially supported by Korea Ministry of Land, Infrastructure, and Transport(MOLIT) as U-CITY Master and Doctor Course Grant Program.

\section{REFERENCES}

[1] Zukin, S., Naked city: the death and life of authentic urban places, Oxford University Press, 2010.

[2] Zukin, S., New Retail Capital and Neighbourhood Change: Boutiques and Gentrification in New York City, City \& Community, 8(1), pp. 47-64, 2009.

[3] Song, A., Symbolic ownership in the commercialization of residential area with a case study of "Yeonhui-dong cafe street”, Seoul National University Press, 2015.

[4] Kim, G., Housing Redevelopment and Neighbourhood Change as a Gentrification Process in Seoul, Korea: A Case Study of Wolgok-4 Dong Redevelopment District, The Journal of Korea Planners Association, 41(4), 2006.

[5] Newman, K. \& Wyly, E.K., Gentrification and Displacement Revisited-A fresh look at the New York City experience, CUCS Research Bulletin, 31, 2006.

[6] Han, K., Study on the determinants of residential satisfaction of public rental housing tenants, Seoul National University Press, 2006.

[7] Choi, Y., Analysis of the Components and Elements Related to Apartment Residential Satisfaction Level, Pusan National University Press, 2005. 